\title{
5
}

\section{Target Suitability and the Crime Drop}

\author{
Nick Tilley, Graham Farrell, and Ronald V. Clarke
}

\section{Introduction}

The initial focus of Felson's routine activity perspective was the crime increases of the 1960s and 1970s that were largely a function of inadvertent changes in everyday life (Cohen \& Felson, 1979). The rise in crime was an unintended side effect of developments in technology, transportation, and domestic life that were widely welcomed. More money, more consumer goods, more labour-saving devices, more transport, and more employment opportunities for women, for example, all brought benefits to citizens, but they also created more crime opportunities and hence sustained increases in crime.

Despite that focus, the routine activity framework that emerged has universal application. It facilitates identification of the mechanisms by which crime patterns and trends occur more generally. It has four central concepts, italicized here: A crime occurs on (1) the interaction of (2) a potential offender and (3) a suitable target in the absence of (4) capable guardianship. The apparent simplicity of these concepts and the framework they represent belies their strength and flexibility. All types of crime, from domestic violence to computer attacks or terrorism, can be addressed using this framework. The framework can be applied to intended as well as unintended impacts on crime, and much of Felson's subsequent research has applied the routine activity perspective in combination with situational crime prevention.

Efforts that are intended to affect crime, particularly those relating to security and environmental design, can be assessed within a routine activity framework. They aim to reduce target suitability, increase capable guardianship, or alter the environment in ways that keep potential 
offenders away from suitable targets. So we suggest that crime falls due to reduced crime opportunities with three origins:

1. Unintended effects of routine activities (changed lifestyles, socioeconomic, political, and technological progress)

2. Intended improvements in security

3. Unintended improvements in security

The first of these falls within the traditional realm of the routine activity approach. An example is the fall in motorcycle theft brought about by enforced legislation requiring that helmets be worn to improve rider and pillion safety (Mayhew et al., 1989). The opportunity for theft was inadvertently reduced, because motorcycle thieves could no longer inconspicuously ride a stolen motorcycle if they did not happen to have a helmet with them. A second example is the shift to non-toxic gas that caused a substantial reduction in suicide in Britain. The removal of a simple and easily available means of killing oneself clearly caused some people to think again (Clarke \& Lester, 1989).

Here we will argue that security improvements were a key and perhaps the main cause of the recent unexpected, sustained, welcome, and widely experienced crime drops (van Dijk \& Tseloni, 2012). Our first contribution is to present new evidence relating to the effects of household security upon burglary. Second, we suggest that some household security improvements may have been at least partly inadvertent - those relating to home improvements, particularly double glazing of doors and windows. Our third contribution is to offer key characteristics of good-quality security - it changes the default to secure, is aesthetically neutral, has a powerful preventive mechanism, is palatable to everyone, is largely effortless to implement, and is rewarding in cost-benefit terms, and we develop this as an acronym. Fourth, we conjecture that an inadvertent consequence of some of these security improvements has included inhibition of early involvement in crime and the onset of criminal careers initiated by that early involvement. In this sense, we suggest there has been an unintended diffusion of benefits beyond the immediate effects of some security measures.

Within the routine activities framework, household security reduces "target suitability." The importance of target suitability in the study of crime has become increasingly apparent. It is now fairly well established that the major declines in car theft in industrialized countries were caused by reduced target suitability in the form of more and better vehicle security. Studies in Australia, the Netherlands, the United 
Kingdom, and the United States all indicate that the spread of electronic immobilizers and central locking, in particular, produced rapid crime drops (Brown, 2004; Kriven \& Ziersch, 2007; Farrell et al., 2011; Fujita \& Maxfield, 2012; van Ours \& Vollaard, 2013). An important implication of these studies is that car crime did not fall for other reasons such as imprisonment, abortion, demographics, changing illicit drug markets, or the range of other explanations that have been offered (Farrell 2013). And so, if those explanations are not applicable for car crime, their validity as explanations for many types of crime is brought into question. Crime drop research focused on the United States is particularly relevant here because violence was long its particular focus despite the fact that the declining car theft trajectory was almost exactly the same as that of violence. In fact, if anything, US violence trends seem to follow those of car theft (Figure 5.1). ${ }^{1}$ And as these crimes continue to decline, we anticipate this is due to continued improvements in car security, such as tracking systems and remote deactivation using on-Star and similar

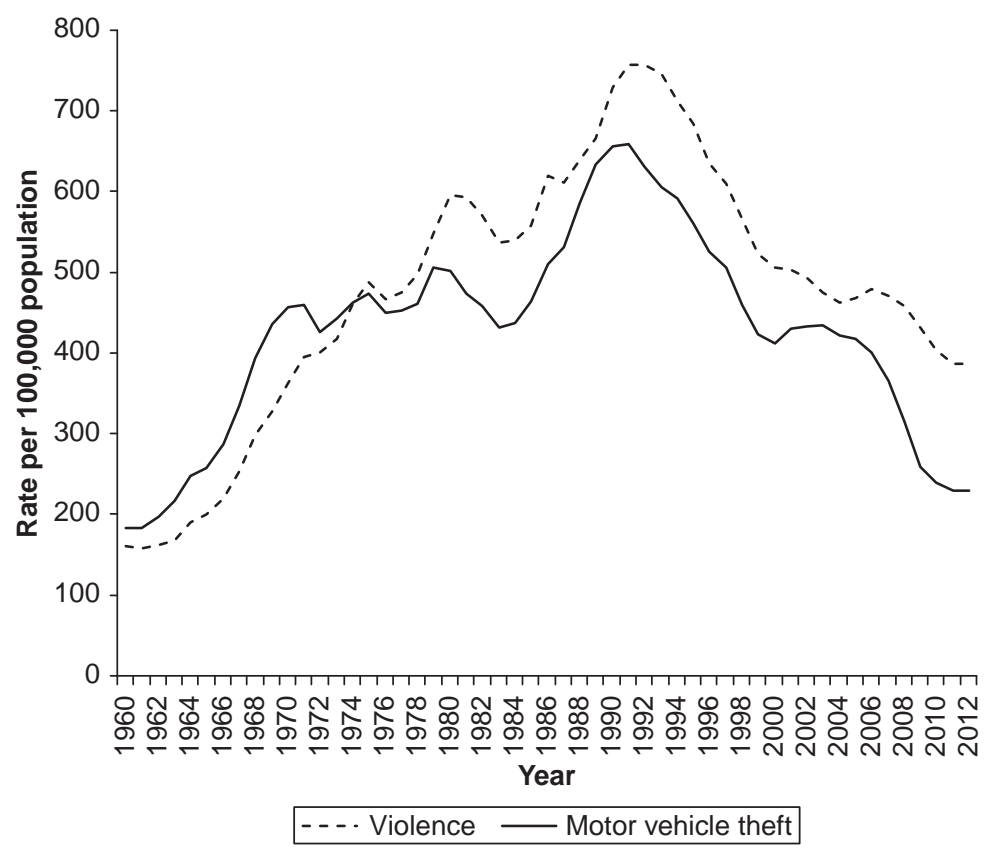

Figure 5.1 Violent crime and motor vehicle theft in the United States, 19602012 (UCR) 
devices. With violence being such a small proportion of overall crime, it is conceivable that it is significantly influenced by trends in car crime and other acquisitive crime.

The car theft studies are a particular instance of the "security hypothesis," which suggests that increases in the quantity and quality of security led to dramatic declines in crime (Farrell et al., 2008, 2011, 2014). Yet, the emphasis of those studies to date has been the quantity of security, reflecting the availability of data that counts the spread of the number of vehicles with different types of security devices.

Indicators of the quality of security have been less readily available. This was not too important for the car crime studies because changes in quantity were much the same as changes in quality. So, while there is some variation in the quality of electronic immobilizer devices and central locking systems, most also tended to be high quality when they spread widely. Hence, quality and quantity increased largely in tandem.

The issue of quality is more important however when it comes to other crime types. We suggest it is fundamental. When it comes to household burglary, for example, door and window locks were already fairly prevalent before burglary started to fall from around 1993 in England and Wales. Hence, our preliminary work suggests that the increase in the prevalence of household security devices is more modest than that relating to vehicle security (Tilley et al., 2011). And while the prevalence of several key security devices increased, this seems to account for far less than all of the decline in household burglary.

Hence, the aspect of the security hypothesis that is emphasized here is improvement in the quality of security. Later, we propose the term "elegant security" for that which embodies quality as well as other desirable characteristics such as good security should be the default option, should not be visually offensive, and should not infringe civil liberties. We suggest the characteristics of elegant security are encapsulated in the acronym "dapper." However, first, we will provide some preliminary evidence that, we suggest, supports the security quality hypothesis.

\section{Context}

The decline in burglary rates in England and Wales was similar to that of other crime types, and the rise in burglary that preceded the 1990s had been similarly steep (Figure 5.2). Yet, attempted burglary did not fall as soon or as far as completed burglaries with entry. This is important, we contend, because burglars continued to try to commit burglary when it 


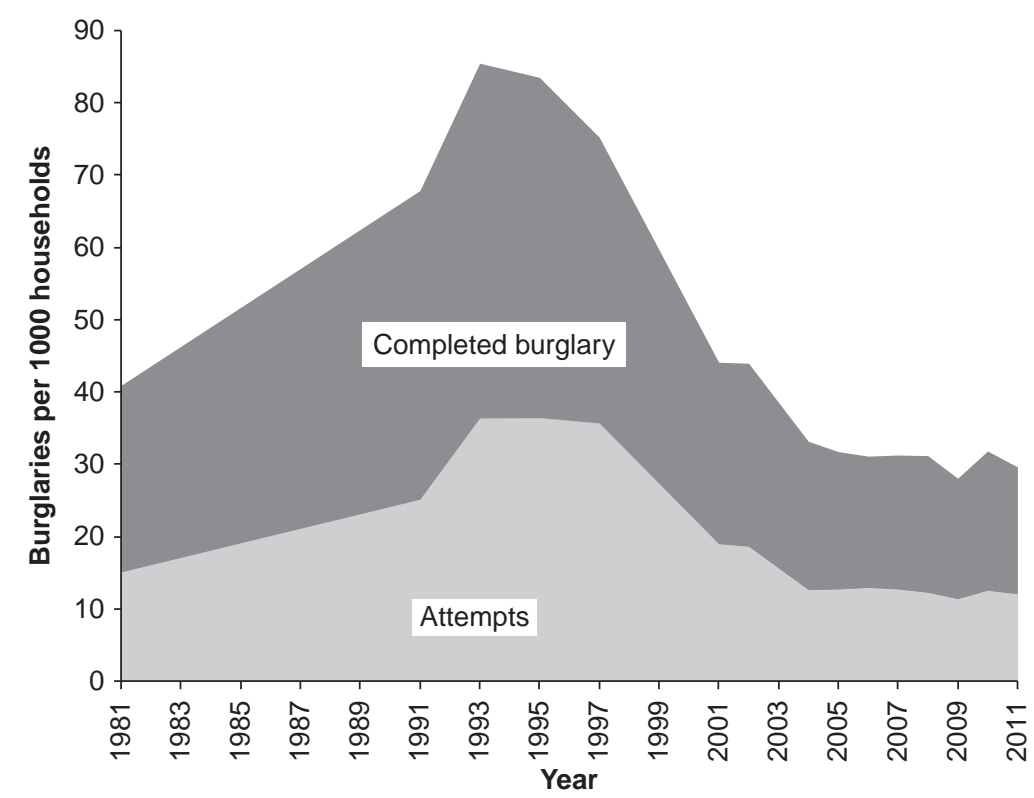

Figure 5.2 Household burglary rate, England and Wales, 1981-2011

became more difficult, resulting in a continued higher level of attempts that then declined, but never as much as completed burglaries.

\section{Security quantity}

Tilley et al. (2011) showed that levels of household security had increased modestly over the course of rapid burglary declines. Hence, the evidence that increases in security caused the decline in household burglary is less convincing than it was for car theft. There is also an inconsistency in the fact that household security devices were fairly widespread before burglary began to decline, and step changes in the volume of security do not comprise a turning point coinciding with the onset of the burglary decline.

Figure 5.3 shows the trends in security device installation from 1992 to 2007/2008 as found in sweeps of the Crime Survey of England and Wales (CSEW - formerly the British Crime Survey). While it shows a steady increase in the availability of most types of device, the exception being window bars/grilles, there is no substantial growth to coincide with the period of rapid fall in domestic burglary. 


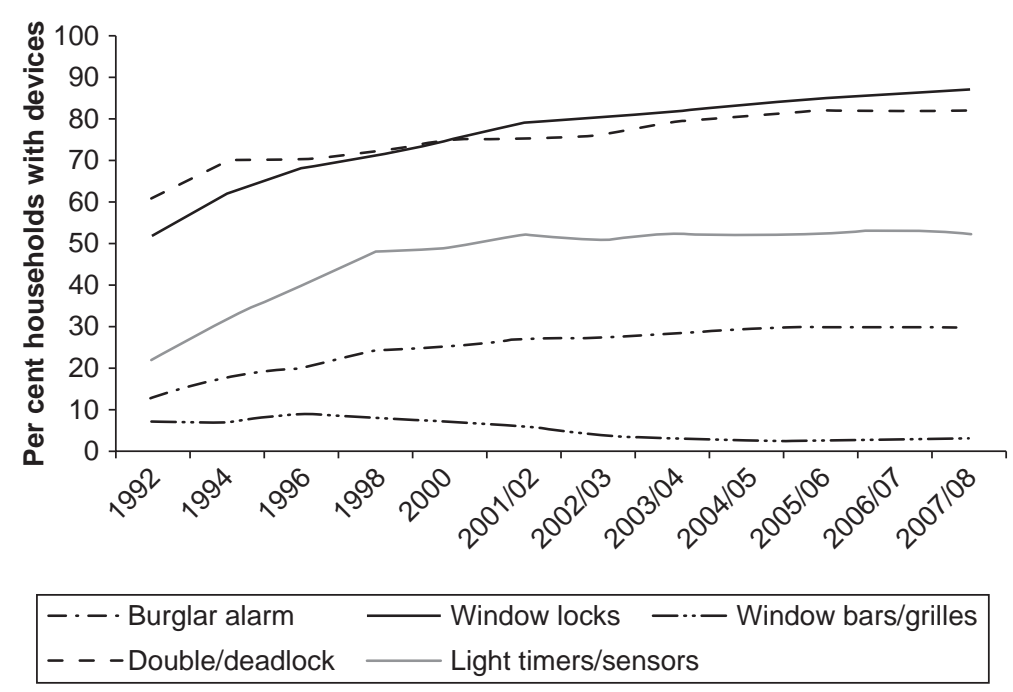

Figure 5.3 Prevalence of household security devices in England and Wales, 1992-2007/2008

This is not to say that the expansion of security device availability had no effect. The CSEW has, indeed, found that properties with more security tend to face lower burglary risk than those with less security. Figure 5.4 draws on data from the 2008/2009 CSEW. It shows that much lower proportions of burglary victims had certain security devices than non-victims. This was the case, most especially, for window locks, double/deadlocks to doors, and outdoor and indoor lights that were either on timers or activated by sensors. But the point here is that, as suggested below, security's aggregate effectiveness increased more rapidly over time than solely its increasing prevalence would indicate, and this cannot be examined in data relating to only one year.

\section{Security quality}

In this section, we present evidence that it was the quality of household security that improved most dramatically. Data from publicly available spreadsheet files on the Office of National Statistics website for 20022011/2012 CSEW sweeps were combined with data from Budd (1999) for 1992-1998 sweeps to give data from 1992 to 2011/2012. The categories of household security available in the earlier source were broader, with window and door locks grouped together, so we grouped the later ones for consistency. Measures of "means of entry" were then put into 


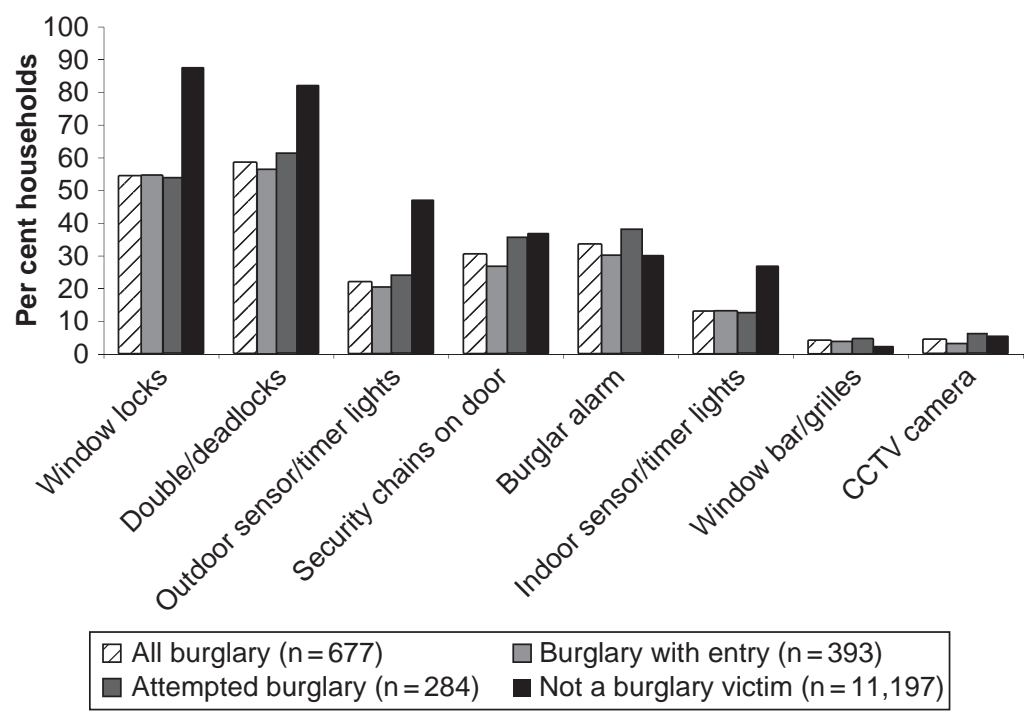

Figure 5.4 Proportion of burglary victims and non-victims with security devices in England and Wales in 2008

two groups - the first relating to efforts that involved breaking-through security, and the second being everything else.

The means of entry categorized as "security overcome" are as follows:

- The forcing of locks on doors, the forcing of locks on windows, the removal or breaking of a door panel, and the removal or breaking of a glass window

The means of entry categorized as "other entry method" are as follows:

- A door (or window) that was already unlocked or open, where the burglar had a key, where the burglar pushed past the occupant, and burglaries involving false presences (deception)

Figure 5.5 presents our main finding. It shows incidence rates for completed burglaries with entry for 1992 onwards. It shows that the decline in burglaries was mainly a decline in those where some type of security was overcome. That is, overcoming security was disproportionately less likely to be the means of entry. From this, in conjunction with the other evidence, we think it reasonable to infer that this was due 


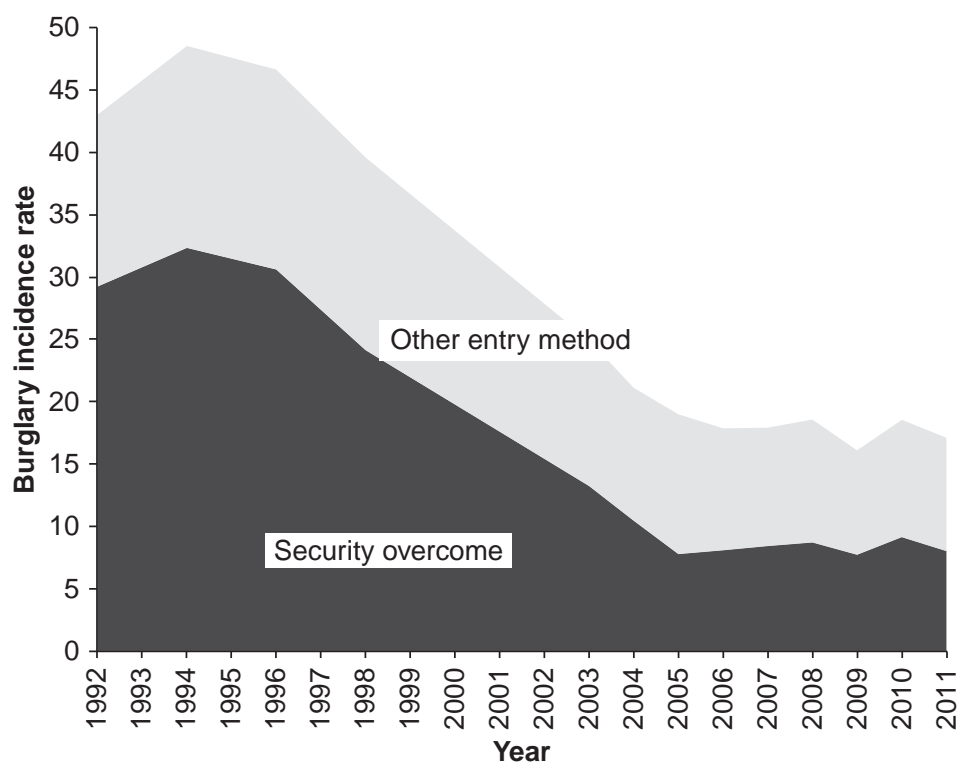

Figure 5.5 Means of entry as indicator of the role of security: Burglary with entry in England and Wales, 1992-2011

to improvements in the quality of the security. Indeed, we can offer no other plausible explanation for this shift in means of entry. And while Figure 5.5 can only show the aggregate effect of both the quality and the quantity of security, this distinguishes it from the more usual measures that relate only to quantity. Future research might seek to parse out that component due solely to quantity.

For the 1996-1998 period, security-related burglaries decline 21 per cent compared to 4 per cent for burglaries with entry by other means. For the 1994-2003 period, burglaries that were security related declined 59 per cent compared to 28 per cent for burglaries by other means.

The year-on-year change in the number of burglaries, where security was overcome relative to others, suggests the decline in burglaries relating to security was earlier and faster (Figure 5.6). It seems telling that burglaries by "other means of entry" fell later and far less dramatically than those relating to security. We suggest the later decline in burglary by other entry methods is an indirect indicator supporting the security quality hypothesis. 


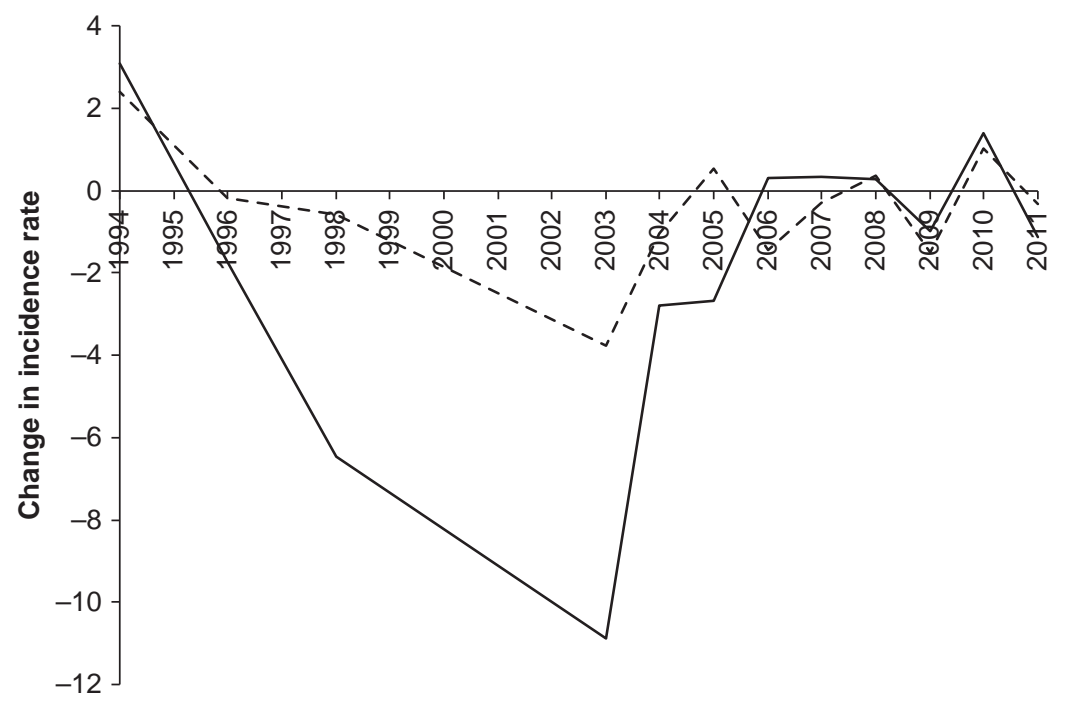

Year

- Security overcome --- Other

Figure 5.6 Year-on-year change in burglaries by entry method, England and Wales, 1994-2011

As we have no alternate explanation for the difference in the trajectories of the two types of entry, it seems reasonable to conclude that it indicates the role of improved household security. If so, the improved quality of household security brought faster and more extensive declines in household burglary and may also have induced a decline in other types of burglary as a diffusion of benefits effect. The prospective offender can no longer rapidly find properties with no or inadequate security and so is less likely to expect and hence look out for such easy opportunities. One conjecture is that there may be a security "tipping point" at which offenders cease to expect easy pickings and hence stop being on the lookout for them. Along those lines, a review of repeat burglary prevention efforts provides preliminary evidence that prevention kicked in when 20 per cent of eligible households had implemented improved security (the tipping point), and that all repeat burglaries were prevented when 80 per cent of households were secured (the remainder falling to diffusion effects) (Grove \& Farrell, 2012).

The importance of this analysis is, we think, as follows. Counts of numbers of security devices do not show changes in the quality of 
particular devices. Door and window locks in particular are much better than they once were, especially when combined with double glazing and home insulation efforts. The result is that, in a survey's counts, a better device still just counts as one device. Further, when it is a new-for-old replacement, no change in the count of devices is registered. So, the finding that there is a greater decline in security-breaking burglaries relative to other means of entry is, we suggest, a signature of the improved quality of household security devices. The next section provides supporting evidence.

\section{The role of double-glazing and home insulation}

We anticipate that, largely hidden in this analysis, the spread of double glazing and better-insulated doors and windows in England and Wales contributed to declining burglary. Here the changes were dramatic. The percentage of dwellings with double glazing to all windows and doors rose from 30 per cent to 71 per cent between 1996 and 2008. It was also in 1994-1997 that standards were set for double glazing in the United Kingdom that would enhance security and avoid the installation of types that had previously enabled panes to be "popped" out (PAS011: 1994, later replaced by BS 7950: 1997 for enhanced security performance of windows for domestic application). ${ }^{2}$ Double glazing has since normally included built-in locks to windows. It is also more difficult to break into, given that there are two sheets of glass and the glass is often toughened. To us, this suggestion is Felsonesque because a consistent theme of Marcus' work has always been to emphasize the unintended consequences of changes in routine activities with quite other purposes than that of influencing crime levels. Here, the greater use of double glazing in England and Wales, in the interests of home comfort and energy saving, may have improved the security of houses by reducing their suitability as targets for burglary once security issues were taken into account in the design. In this case, the increase in security is somewhat inadvertent. The evidence is suggestive of a double-glazing effect, although far from conclusive. Figure 5.7 plots the change in percentage of properties with full double glazing against changes in the proportion of burglaries with entry through the window. The number of burglaries was also dropping between 1996 and 2008 in England and Wales. The percentage fall in burglaries with entry through the window fell by 70 per cent, while those by entry using other means (principally the door) fell by only 20 per cent.

We are presently unable to offer an explanation relating to the decline in household burglary in the United States. That decline appears to 


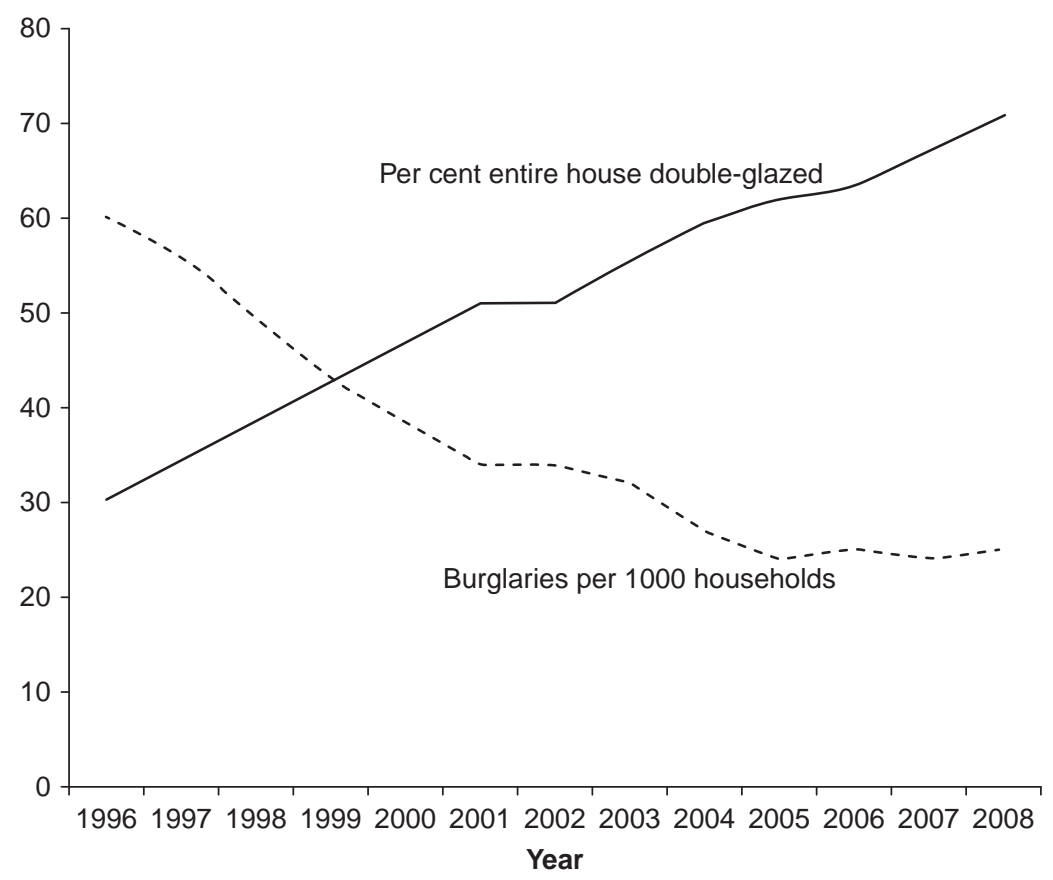

Figure 5.7 Changes in levels of full double glazing and burglary with entry, 1996-2008

begin in the 1970s. Examining double glazing and insulation may not directly transfer to the United States. The housing stock is, on average, somewhat different, with far more wooden structure housing than in England and Wales. Likewise, air conditioning (AC) tends to be more prevalent in the United States, and while in-window AC units could facilitate burglary (because that window becomes a potential source of ingress), built-in household AC seems likely to encourage more routine closing of doors and windows. However, even this brief discussion indicates the importance of pursuing research into the security hypothesis via different avenues in different contexts.

\section{Elegant security}

The security hypothesis suggests that some closer definition of quality is required. Clearly, effectiveness in crime prevention is critical. But that might be achieved by a variety of means. Further, truly elegant security 
Table 5.1 Characteristics of quality security

\begin{tabular}{ll}
\hline $\begin{array}{l}\text { Default } \\
\text { Aesthetic }\end{array}$ & $\begin{array}{l}\text { The default condition is secure rather than insecure. } \\
\text { It is aesthetically neutral or pleasing. } \\
\text { It has a powerful preventive mechanism that is not easily } \\
\text { circumvented. }\end{array}$ \\
$\begin{array}{l}\text { It is principled and acceptable to all, often increasing liberty and } \\
\text { freedom. }\end{array}$ \\
$\begin{array}{l}\text { Effortless } \\
\text { Rewarding }\end{array}$ & $\begin{array}{l}\text { It is effortless, taking little or no time and effort to engage. } \\
\text { It brings preventive rewards greater than its cost. }\end{array}$ \\
\hline
\end{tabular}

has other qualities that are easy to overlook. In fact, the best security can be so unobtrusive that it is difficult to recognize it as security without close scrutiny. Table 5.1 identifies preferable characteristics of elegant security (producing the acronym dapper).

Let us look at modern car security in these terms as an example. The key-button activation of secure locks, reliable alarms, and high-quality electronic immobilizers fitted to the vast majority of new cars comprises dapper security for vehicles. Hence, this specific description of dapper is as follows:

- Default: The default condition of new vehicles is secure because central locking and immobilizers activate automatically and remotely.

- Aesthetic: They are largely unseen - unlike older add-on security such as crook-locks.

- Powerful: They are very difficult to by-pass or overcome (unlike previous generations of door locks and steering wheel locks).

- Principled: They are unambiguously acceptable to all (except car thieves).

- Effortless: The effort involved in both leaving the car secure and deactivating the security measures when wanting to drive away is minimal.

- Rewarding: When built-in during manufacture, alarms, electronic immobilizers, and strong locks add little cost to the vehicle (but reduce crime costs enormously).

Other developments in car security, including locked fuel caps that can be opened from inside the car, widely distributed sound-system components, automatically retracted wing mirrors, and aerials fitted flush to the roof of the car also furnish elegant "dapper" security to vehicles. 
Examples of prior, poorer quality vehicle security include steering wheel locks and retrofitted mechanical immobilizers. Steering wheel locks were fitted to all new vehicles in the United Kingdom from 1970 to 1971 (Webb, 1994, p.73). They were not fitted to older cars. They were not general. They were associated with immediate widespread displacement to older vehicles. They were also not trouble free. Offenders soon found ways of overcoming them, and these methods generally involved breaking the locking mechanism.

Security in housing can likewise be more or less dapper. Take double glazing as an example.

- Default: Double-paned windows are naturally more resistant to breaking, more so if newer glass is more resistant. Newer locks are built-in and automatic.

- Aesthetic: Some (usually older) double glazing was ugly but most can now be attractive.

- Powerful: It used to be that lockless windows were easily opened, and older, fragile, single-pane glass was easily broken. Then retrofit locks were poor and easily neglected. Each of the frame and fittings, double-paned resistant glass, and integrated frame locks (perhaps combined with electronic alerts or alarms in some systems) offers far greater protection.

- Principled: Double glazing requires no more maintenance than single glazing. Indeed, hardwood, plastic, and aluminium require less.

- Effortless: Double glazing requires no effort. Window locks are normally built into the catches that operate when a window is shut.

- Rewarding: Double glazing brings savings in terms of energy consumption plus reduced global warming. It is inexpensively built into new housing and replacement glazing. The reduced costs of crime are a potentially significant bonus.

In contrast, guns, walled communities, bars, grilles, and guards are far less elegant methods of trying to reduce burglary. They require effort and/or interfere with users' and others' everyday lives and/or are high cost and/or are in the hands of only a minority and/or are aesthetically displeasing and/or are not needed and/or cause trouble by way of maintenance.

How should high-quality security replace low-quality security or no security? There appear to be several mechanisms. First, crime rates increase precipitously, and this provokes pressure on manufacturers and/or builders to improve security. The pressure might come directly 
from consumers. However, it tends to come from third parties. One third party comprises insurance companies, which bear the costs of insured claims and which may incentivize consumers to demand better security as a condition for insurance cover or as a basis for reduced premiums (for example, requirements that household security improvements be made following a burglary as a condition for continued insurance or reduction in the hike in premiums that would otherwise be made). A second third party comprises central or local government that can either require security (for example, minimum standard electronic immobilizers) or leverage change by threatening regulation (for example, the substitution of tokens for cash in household prepayment metres for gas and electricity). A third third party comprises consumer groups, which can draw attention to weaknesses in the security of products and places and the scope there is for reducing vulnerability (for example, Which magazine's comparative assessment of vehicle security). A fourth third party comprises the police, who are well placed to identify risky products and alert those in a position to the need for improved security (for example, efforts to secure trolleys from theft of purses and encouragement of kite marking for secure double glazing). Once the demand for improved security is in place, then competitive pressures may be released to improve it, at which point evolutionary pressures towards improvement in the direction of elegance can be expected, perhaps backed by regulation requiring minimum standards.

Thus, market-based incentives can be used to promote good-quality security over time. The research community has a role to play in fostering such pressures, as they have in devising elegant security solutions. Identifying products and places that are highly vulnerable requires research acumen. In the United Kingdom, the production of early car theft indices is an example of a research endeavour that provided systematic statistical evidence of which makes and models of car were most vulnerable to theft. Its authoritative publication by the Home Office led to rapid innovations in vehicle security and consequential falls in car crime (Laycock, 2004). More recent moves towards a phone theft index aspire to similarly elegant goals (Mailley et al., 2008; Beckford, 2013).

Of course, in some cases, changes are more serendipitous. The major crime increases of the 1960s-1990s, as Marcus Felson argues, were unintended effects of changes brought about for other reasons to do with routine activities. Likewise, it seems that the spread in use of double glazing (notably when security issues in its use had been addressed) may well have furnished an elegant crime prevention device despite this not being the main rationale for its installation. 


\section{Diffusions of security benefit}

We note three possible mechanisms here, which may operate individually or jointly. First, some crimes facilitate others. The theft of cars, for example, facilitates crimes that require transportation in vehicles that cannot be traced to their drivers, such as large-scale burglary and armed robbery. If car theft is inhibited, access to a facilitator of other crimes is thereby also reduced, with criminals largely denied use of the road. Second, car crime and burglary are high-volume gateway or debut crimes, normally undertaken initially in the company of other more experienced co-offenders who thereby induct neophyte offenders into (routinized) criminality. Reducing the ease of car theft and burglary thereby reduces a significant pathway into criminality. A third possibility is that security-generated reductions in opportunity for car theft and burglary inhibit adolescence-limited occasional and prolific offending, perhaps with a lesser effect upon life-time persistent offending. Here, we might expect that a rump of long-term prolific offenders will be more likely to persist in their criminal behaviour, but that there will be a lasting crime-inhibiting legacy from those whose criminal careers never take off (Farrell et al., 2014). For now, the argument is that the inadvertence emphasized by Marcus in relation to secular changes in everyday life as a source of crime increases in the 1960s and 1970s may also operate in the context of beneficial side effects following the intentional prevention of specific crimes through security improvements.

\section{Summary and conclusions}

The routine activities perspective was proposed to explain why crime rates had increased from the 1960s as an inadvertent consequence of changes in everyday life at a time of prosperity and when many social problems were becoming less severe than they had been previously. Much of criminology still ignores the evidence that changes in targets, the environment, and movement patterns are fundamental in determining crime rates as well as being far more amenable to public policy intervention. And such interventions can be stimulated by market-based incentives.

This chapter provided an argument plus preliminary evidence that the quality of security was critical to the drop in residential burglary of the 1990s. We suggest that the role of quality was easy to overlook in the study of car theft because the new security devices that increased in quantity were also of higher quality. When it comes to household 
security, the picture is more complex because many of the better-quality devices went by the same old names as before - door and window locks in particular. The quality of newer replacement locks and windows, partly driven by double glazing and home insulation efforts, was less easy to measure directly. We view the present study as providing additional evidence in support of the security hypothesis while recognizing that further research and further evidence from other sources would be beneficial. Moreover, we conjecture that an inadvertent diffusion of benefits from the security-induced reductions in car crime and burglary may include the inhibition of wider criminal activities. Reflecting the specific rather than general mechanisms by which we anticipate diffusion occurred in the context of the crime drop, this has elsewhere been termed "the keystone hypothesis" (Farrell et al. 2011, 2014).

In conclusion, if the security hypothesis is to be more generally accepted, we believe that more longitudinal analyses of drops in specific crimes beyond the existing ones of vehicle theft and burglary are required. For example, detailed analyses of this kind might examine the retail sector's continuing efforts to reduce shop theft, the efforts made by the banks to reduce robbery, the work of credit card companies to reduce fraud and identity theft, and hoteliers' ongoing efforts to reduce crimes against their guests and their premises. Without evidence of this kind, the car theft and burglary analyses for the crime drop are in danger of being seen as special cases without general application. The beginnings of the necessary work can be found in some situational crime prevention case studies, but rarely with the detail needed to support the security hypothesis.

In addition to more detailed analyses of specific kinds of crimes, a more complete theory of the mechanisms at work in producing the crime drop is also needed if the hypothesis is to gain general acceptance among criminologists. This chapter has contributed to this theory in three ways: first, by proposing in the Introduction that there are three kinds of crime drops; second, by providing evidence of the role of quality security; and third, by speculating further on the keystone hypothesis which refers to the diffusion of benefits resulting from the decline of specific categories of crime. However, many other factors will be needed to explain how such a complex phenomenon as a crime drop occurs. van Dijk (2012) has suggested that "opportunity theory" could provide the guiding framework for identifying these factors while we have suggested above that Routine Activity Theory could serve the same role. While a "theory" of crime drops (and crime increases) will benefit academic criminologists and crime scientists, who might 
be expected to understand these phenomena, the longer-term goal is even more important. It is to enable them to provide advice, based on sound theory, on ways for policymakers and industry leaders to avoid future crime increases, and promote crime drops, within their particular spheres of influence. Without Marcus' pioneering work, this might seem not merely a highly ambitious goal but one that was completely unattainable.

\section{Acknowledgement}

The first two authors acknowledge the Economic and Social Research Council Secondary Data Analysis Initiative Phase I grant (project REF: ESRC-SDAI (ES/K003771/1) and their ongoing collaboration with Andromachi Tseloni, Louise Grove, and Rebecca Thompson. Funding was provided by University College London for the open access charge.

\section{Notes}

1. The correlation between violence and motor vehicle theft rates from 1960 to 2012 is a remarkable 0.89 , increasing to 0.92 when violence is lagged by two years.

2. Details are found at: http://thecrimepreventionwebsite.com/windows-of -enhanced-security-pas-242012-formerly-bs-7950/585/the-development-of -enhanced-security-windows/. Standards were subsequently set in the Netherlands, then the rest of continental Europe.

\section{References}

Beckford, M. (2013). Is your phone the one most likely to be stolen? Downing street to publish "risk index" of handsets to encourage shoppers to buy safer models. The Daily Mail, 20 July 2013, at http://www.dailymail.co.uk/ news/article-2371797/Downing-Street-publish-risk-index-phones-advise-safer -models.html, Accessed 29 January 2014.

Budd, T. (1999). Burglary of domestic dwellings: Findings from the British crime survey. Home Office Bulletin 4/99. London: Home Office.

Brown, R. (2004). The effectiveness of electronic immobilisation: Changing patterns of temporary and permanent vehicle theft. In M. G. Maxfield \& R. V. Clarke (Eds.), Understanding and preventing car theft. Monsey, NY: Criminal Justice Press. pp. 101-119.

Clarke, R. V., \& Lester, D. (1989). Suicide: Closing the exits. New York, NY: SpringerVerlag.

Cohen, L., \& Felson, M. (1979). Social change and crime rate trends: A routine activity approach. American Sociological Review, 44, 588-608.

Farrell, G. (2013). Five tests for a theory of the crime drop. Crime Science, 2(5) 1-8. 
Farrell, G., Tilley, N. and Tseloni, A. (2014). Why the crime drop. In M. Tonry (Ed.), Why Crime Rates Fall and Why They Don't, volume 43 of Crime and Justice. Chicago: University of Chicago Press.

Farrell, G., Tilley, N., Tseloni, A., \& Mailley, J. (2008). The crime drop and the security hypothesis. British Society of Criminology Newsletter, 62, 17-21.

Farrell, G., Tilley, N., Tseloni, A., \& Mailley, J. (2011). The crime drop and the security hypothesis. Journal of Research in Crime and Delinquency, 48, 147-175.

Fujita, S., \& Maxfield, M. (2012). Security and the drop in car theft in the United States. In J. J. M. van Dijk, A. Tseloni, \& G. Farrell (Eds.), The international crime drop: New directions in research. Basingstoke: Palgrave Macmillan. pp. 231-249.

Kriven, S., \& Ziersch, E. (2007). New car security and shifting vehicle theft patterns in Australia. Security Journal, 20, 111-122.

Laycock, G. (2004). The U.K. Car Theft Index: An example of government leverage. Crime Prevention Studies, 17, 25-44.

Mayhew, P., Clarke, R., \& Elliot, D. (1989). Motorcycle theft, helmet legislation and displacement. Howard Journal of Criminal Justice, 28, 1-8.

Tilley, N., Tseloni, A., \& Farrell, G. (2011). Income disparities of burglary risk: Security availability and the crime drop. British Journal of Criminology, 51, 296-313.

van Ours, J. C., \& Vollaard, B. (2013). The engine immobilizer: A non-starter for car thieves. CESifo Working Paper: Public Choice, No. 4092. Centre for Economic Studies and IfoInstitute. Munich: University of Munich.

van Dijk, J. J. M. (2012). Closing the doors. Stockholm Prizewinner's Lecture 2012, at http://www.criminologysymposium.com/symposium/event -information/video-clips/previous-years.html. Accessed 30 April 2014.

van Dijk, J. J. M., \& Tseloni, A. (2012). Global overview: International trends in victimization and recorded crime. In J. J. M. van Dijk, A. Tseloni, \& G. Farrell (Eds.), The international crime drop: New directions in research. London: Palgrave Macmillan. pp. 11-36.

Webb, B. (1994). Steering column locks and motor vehicle theft: Evaluations from three countries. Crime Prevention Studies, 2, 71-89. 